\title{
An Experimental Study on Various Industrial Wastes in Concrete for Sustainable Construction
}

\author{
Sanjay R. Salla ${ }^{1 *}$, Chetankumar D. Modhera ${ }^{2}$ and Uppara Raghu Babu ${ }^{3}$
}

\begin{abstract}
The current era shows that innovation and reuse of industrial by-products are necessary to protect the environment and sustainable development. The production of cement highly harms the environment in terms of $\mathrm{CO}_{2}$ emissions. Cement production contributes to nearly $5.0 \%$ of the global pollution that is induced by $\mathrm{CO}_{2}$ emissions. The present study shows the role of supplementary cementitious materials (SCMs) in construction industries. The two different SCMs, namely cinder and processed granulated ground blast furnace slag (GGBS), were used to replace cement. Different blends were prepared by replacing ordinary Portland cement (OPC) with cinder up to $70 \%$ intervals of $10 \%$ and up to $50 \%$ of processed GGBS at 5\% intervals. The different tests were conducted like specific gravity, setting time, fineness, and compressive strength of different prepared blends to ensure the pozzolanic reactivity of SCMs. X-ray fluorescence (XRF) test results showed that available oxides like calcium, silica, aluminum, and iron oxides are suitable for replacing cement with cinder and processed GGBS. In addition to these, to find out possible optimum among the various prepared blends, techniques for order performance by similarity to ideal solution method was adopted. Cost analysis shows that the overall cost of material can be reduced by $16 \%$. Energy analysis shows that cinder and processed GGBS could reduce energy consumption by $24.56 \%$ and $3.6 \%$, respectively.
\end{abstract}

\section{Theoretical background}

Construction is the second-largest economic activity (after farming) in India, and concrete is the second-highest consuming material after water on this planet. The current era shows that innovation and reuse of industrial by-products are necessary to protect the environment and sustainable development. The current $\mathrm{CO}_{2}$ concentration is $408.52 \mathrm{ppm}$, and according to the world economic forum in 2017 , India was the third in $\mathrm{CO}_{2}$ emission at a global level with $6.8 \%$ after china $(27.2 \%)$ and the US (14.6\%). The production of cement highly harms the environment in terms of $\mathrm{CO}_{2}$ emissions. Cement production contributes nearer to $5.0 \%$ of global pollution induced by $\mathrm{CO}_{2}$ emission. Cement is only the essential material to satisfy global housing and modern infrastructure needs. The growth of cement industries is worldwide, but it faces many challenges like manufacturing process changes, fuel sources, and change in the primary raw material. Many researchers are working on alternative fuels in cement production in this era,

\footnotetext{
${ }^{1}$ Research Scholar, Civil Engineering Department, Sardar Vallabhbhai National Institute of Technology, Surat, India. *Corresponding author,

E-mail: er.sallasanjay@gmail.com

${ }^{2}$ Professor, Civil Engineering Department, Sardar Vallabhbhai National Institute of Technology, Surat, India.

${ }^{3}$ Assistant Professor, Department of Civil Engineering, Srinivasa Ramanujan Institute of Technology, Anantapuramu, Andhra Pradesh, India.
}

changing the available binder's chemical properties, and working on industrial by-products used as supplementary cementitious materials. The utilization of SCMs is necessary to reduce the consumption of cement. The present study shows the role of SCMs in construction industries and the use of two different SCMs, cinder and processed GGBS, used in partial replacement of cement.

Concrete is divided into two different phases, namely the aggregate phase and the cement paste phase. The cement phase contains only binder (cement and supplementary cementitious material) and water. The cement paste phase contains fine aggregate, coarse aggregate, chemical admixture, and mineral admixtures as per the need (Nilesen and Monteiro 1993; Mehta and Monteiro 2017). The conventional concrete generally contains $10 \%$ to $15 \%$ of cement/binder, $70 \%$ to $80 \%$ of aggregate, $10 \%$ to $15 \%$ of water and entrapped air content ranges $1 \%$ to $5 \%$. Recent research scenario is focused on cement alternatives, industrial by-products, alternatives of raw material used to produce clinker. The uses of SCMs are widely accepted worldwide in cement production, with cement as a partial replacement or preparing different blends with different supplementary cementitious material, or else direct use in concrete for sustainable development (Siddique and Khan 2011). The utilization of such materials means SCMs or alternative materials to reduce $\mathrm{CO}_{2}$ emissions. However, this is one way to use industrial by-products in the concrete industry, which reduces disposal problems and environmental problems caused by industrial waste. It is clear from the earlier discussion that the use of industrial by-products and recycling of materials is essential for reducing environmental impact and sustainable development. In 
other words, the 3R (Reduce - Reuse - Recycle) policy is needed for sustainable and eco-friendly development.

According to the US Department of Transportation, steel slag is a result of steel making. It is formed during the division of the liquid steel from degradations in steel-production heaters. The slag is formed as a liquid fluid and is an intricate arrangement of silicates and oxides that sets after cooling. There are a few different types of steel slag formed during the steel production process. These various slags are referred to as heater or tap slag, raker slag, engineered (scoop slags), cinder, and pit slag (cleanout slag). Presently, China utilizes steel slag on a large scale to produce cement, concrete, and straight incorporation in the road and hydraulic construction (Yi et al. 2012). The main mineral phases identified in the electric arc furnace ladle slag were Portlandite, Mayenite, and Malenterite. X-ray diffraction (XRD) analysis of both the basic oxygen furnace and electric arc furnace ladle slag indicated the presence of free magnesium oxide and calcium oxide (Yildirim and Prezzi 2011). The setting-time and water absorption properties of concrete made of steel slag and OPC are similar to those made with only OPC, but it gives more compressive strength. The utilization of steel slag is feasible based on experimental results and the lower cost of the material. It is also utilized as the producer or contributor to reducing binders' cost (Tsakiridis et al. 2008a).

Processed GGBS is a finer granulated powder of granulated ground blast furnace slag, also known as Alccofine (Kumar et al. 2018). Fineness increases the properties of standard GGBS like high surface area, better-quality workable properties, and high resistivity to chemical attack. Processed GGBS is another age supplementary cementitious material with inherent cutting-edge content. Despite its high fineness, it does not increase water demand at the dosage of 5 to 15 percent of typical ordinary Portland cement by and large. Concrete slump is seen to be improved due to the dense packing of cementitious material, producing low void content. The use of processed GGBS results in a hydrated cement matrix to comprise of microscopic pores. Processed GGBS is a uniquely prepared item dependent on high glass content with high reactivity acquired through controlled granulation. The crude materials are made essential out of low calcium silicates. The computed Blaine value based on particle size distribution is around 700 to $800 \mathrm{~m}^{2} / \mathrm{kg}$ and is truly fine (Teng et al. 2013).

Processed GGBS can likewise be utilized as a high range water reducer to improve compressive strength or higher workability, enhancing the flow. The advantages of processed GGBS are observed in the concrete mix design; the initial strength development rate was increased or similar to that of silica fume. The utilization of Alccofine increases the fresh and hardened properties and higher particle packing density of fly-ash based geopolymer concrete (Saloni et al. 2020). The Alccofine significantly affects the mechanical and microstructural properties of fly-ash-based geopolymer concrete (Parveen
Table 1 Chemical composition of materials.

(All the available oxides are shown in terms of percentage by mass)

\begin{tabular}{|c|c|c|}
\hline Element & Cinder (\%) & Processed GGBS (\%) \\
\hline $\mathrm{CaO}$ & 49.78 & 25.25 \\
\hline $\mathrm{SiO}_{2}$ & 6.99 & 40.08 \\
\hline $\mathbf{A l}_{2} \mathbf{O}_{3}$ & 9.39 & 10.00 \\
\hline $\mathrm{Fe}_{2} \mathrm{O}_{3}$ & 17.77 & 2.85 \\
\hline MgO & 2.99 & 7.01 \\
\hline $\mathrm{Na}_{2} \mathrm{O}$ & 0.23 & 0.25 \\
\hline $\mathbf{K}_{2} \mathbf{O}$ & N/A & 0.27 \\
\hline $\mathrm{SO}_{3}$ & 3.92 & 12.64 \\
\hline $\mathrm{TiO}_{2}$ & 1.33 & 0.60 \\
\hline MnO & 4.38 & 0.33 \\
\hline $\mathrm{ZnO}$ & 0.28 & N/A \\
\hline SrO & 0.36 & 0.28 \\
\hline $\mathrm{RuO}_{2}$ & 0.95 & N/A \\
\hline $\mathrm{ZrO}_{2}$ & 0.14 & 0.17 \\
\hline $\mathrm{Cr}_{2} \mathrm{O}_{3}$ & 0.31 & N/A \\
\hline $\mathrm{Nb}_{2} \mathrm{O}_{5}$ & 0.39 & N/A \\
\hline $\mathbf{R} \mathbf{b}_{2} \mathbf{O}$ & N/A & 0.01 \\
\hline Total & 99.21 & 99.74 \\
\hline
\end{tabular}

N/A: Oxides were not available or not found.

et al. 2018). The higher specific surface area of ultrafine GGBS gives higher hydration and pozzolanic reaction. In addition, it shows a consistent mix and improvement in fresh properties like the workability and consistency of concrete. Moreover, the improvement was observed in compressive strength and durability aspects (Teng et al. 2013). The self-compacting concrete used silica fume and ultrafine GGBS. The study noted that $6 \%$ silica fume and $8 \%$ ultrafine GGBS (Alccofine) give high compressive strength. This proportion was decided based on the statistical approach using the design of experiment (DOE) method (Mohan and Mini 2018). Ultrafine GGBS with calcium nitrate as an admixture decreases the corrosion potentials of specimens tested up to 50 days at 10 day intervals. Besides this, it decreases the workability and water absorption in concrete, but increases the compressive strength up to $18 \%$ (Kumar et al. 2018). Some researchers also reported a negative impact on the ternary blend by using Alccofine (ultrafine GGBS) with GGBS; the combination of GGBS and Alccofine as cement replacement would not be useful to prepare ternary blend concrete (Narender Reddy and Meena 2018).

\section{Experimental materials cinder and proc- essed GGBS}

\subsection{Chemical compositions}

The chemical composition in the materials evaluated by XRF analysis shows the existence of available oxides of calcium, silica, aluminum, magnesium, and sulfur. The wet chemistry analysis method gives Bogue's compound (Taylor 1989) $\left(\mathrm{C}_{3} \mathrm{~S}, \mathrm{C}_{2} \mathrm{~S}, \mathrm{C}_{3} \mathrm{~A}\right.$, and $\mathrm{C}_{4} \mathrm{AF}$ ), which were calculated Bogue's by equations. In the present study, cinder and processed GGBS were collected from locally available steel industries. Table 1 shows the XRF analysis of cinder and processed GGBS. 
The XRF analysis shows that cinder contains $\mathrm{CaO}$ : $49.78 \%, \mathrm{SiO}_{2}: 6.99 \%, \mathrm{Al}_{2} \mathrm{O}_{3}: 9.39 \%, \mathrm{Fe}_{2} \mathrm{O}_{3}: 17.77 \%$, MgO: $2.99 \%, \mathrm{SO}_{3}: 3.92 \%, \mathrm{TiO}_{2}: 1.33 \%, \mathrm{MnO}: 4.38 \%$ and alkalis: $0.23 \%$. Other researchers reported that the composition of steel slag ranges as, $\mathrm{CaO}: 42$ to $60 \%$, $\mathrm{SiO}_{2}: 10$ to $20 \%, \mathrm{Al}_{2} \mathrm{O}_{3}: 1$ to $7 \%, \mathrm{MgO}: 3$ to $13 \%, \mathrm{Fe}_{2} \mathrm{O}_{3}$ : 3 to $9 \%$ (Humbert and Castro-Gomes 2019). However, Mo et al. (2016) reported a high $\mathrm{Fe}_{2} \mathrm{O}_{3}$ at $27.27 \%$. While comparing the composition of cinder and steel slag, it is observed that the cinder composition falls in the range of steel slag. Nevertheless, there is a higher amount of iron oxides also observed in cinder than steel slag. The observed loss on ignition value for cinder was $1.09 \%$.

The XRF analysis shows that processed GGBS contains $\mathrm{CaO}: 25.25 \%, \mathrm{SiO}_{2}: 40.08 \%, \mathrm{Al}_{2} \mathrm{O}_{3}: 10 \%, \mathrm{Fe}_{2} \mathrm{O}_{3}$ : 2.85\%, MgO: $7.01 \%, \mathrm{SO}_{3}: 12.64 \%, \mathrm{TiO}_{2}: 0.60 \%, \mathrm{MnO}$ : $0.33 \%$ and alkalis $\left(\mathrm{Na}_{2} \mathrm{O}+\mathrm{K}_{2} \mathrm{O}\right): 0.48 \%$. Teng et al.
(2013) have reported that the ultrafine GGBS (Alccofine) contains $\mathrm{CaO}: 35.1 \%, \mathrm{SiO}_{2}: 31.2 \%, \mathrm{Al}_{2} \mathrm{O}_{3}: 9 \%, \mathrm{Fe}_{2} \mathrm{O}_{3}$ : 1\%, $\mathrm{MgO}: 11.8 \%, \mathrm{SO}_{3}: 0.1 \%$. The observed loss on ignition value for processed GGBS was $4.68 \%$.

Figures 1 and 2 how the X-ray diffraction (XRD analysis) pattern of cinder and processed GGBS. The $\mathrm{X}$-ray diffraction pattern of cinder and processed GGBS shows that alite, yeelimite, periclase, quartz, and calcium oxides are present. As shown in Fig. 1, crystalline calcium silicates are present in cinder, and the peaks of tricalcium silicates were observed at $29.3^{\circ}$ and $49.8^{\circ} 2 \theta$. Similarly, as shown in Fig. 2 in processed GGBS, the peaks of tricalcium silicates were observed between $30.2^{\circ}$ to $32.8^{\circ} 2 \theta$ shows the presence of alite, which is the primary strength contributing phase during hydration (Nicolae et al. 2007; Tsakiridis et al. 2008b). However, in the presence of quartz and iron oxides were observed

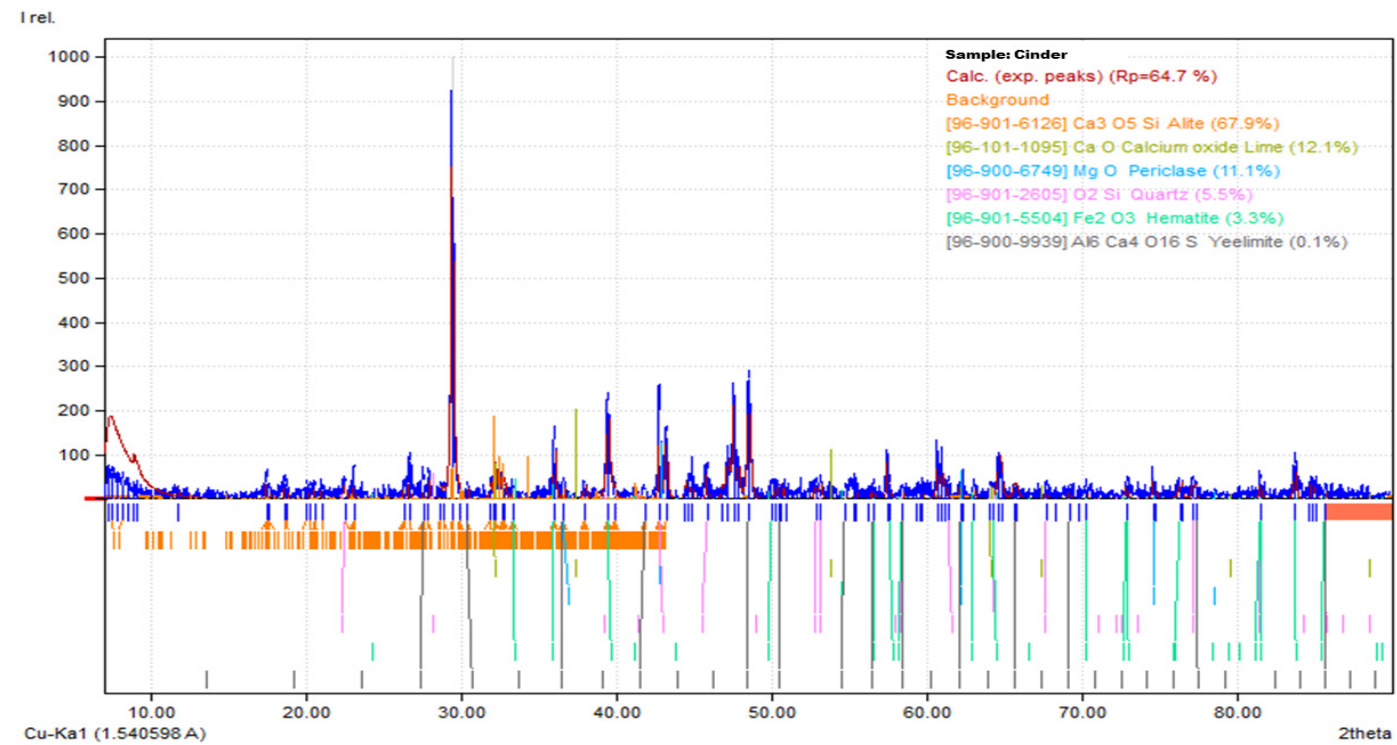

Fig. 1 X-ray diffraction pattern of cinder.

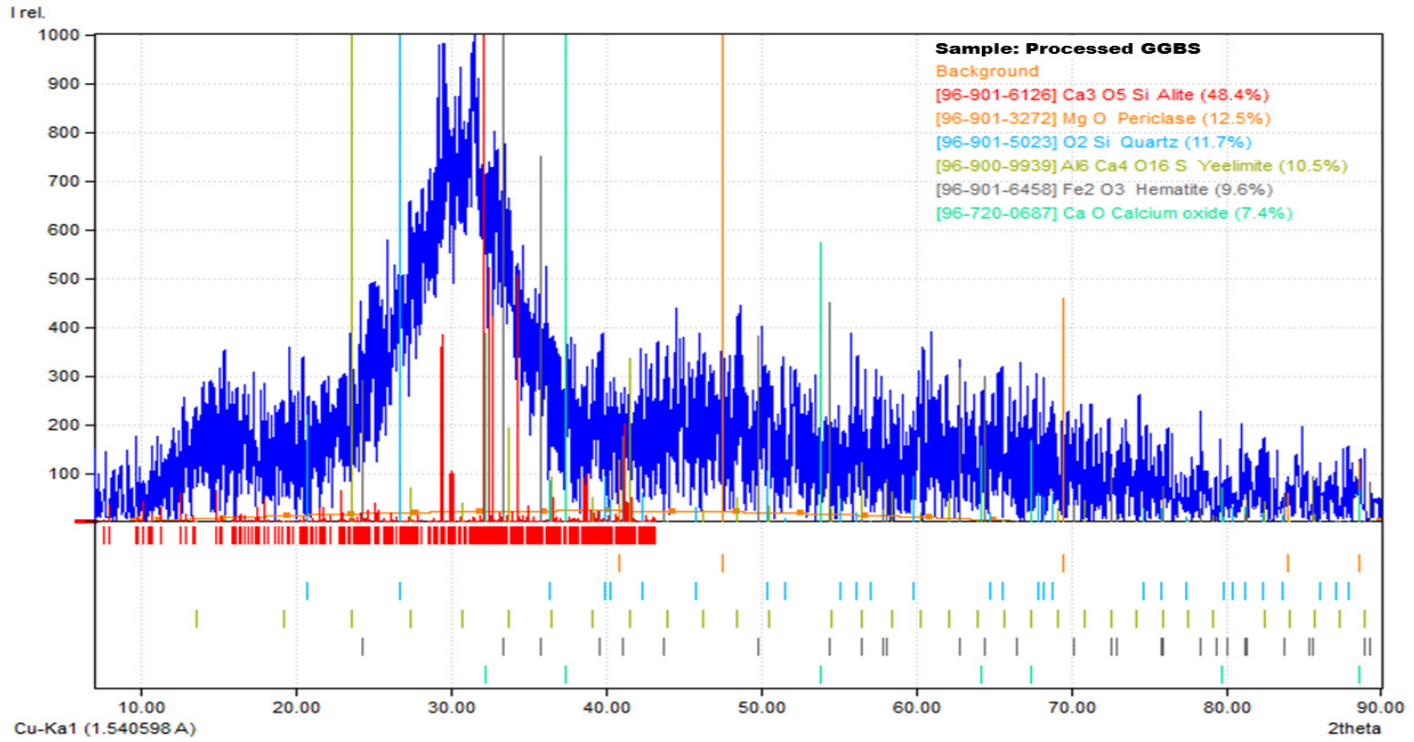

Fig. 2 X-ray diffraction pattern of processed GGBS. 
from the results of XRD analysis. In cinder, the amount of iron oxide is higher compare to processed GGBS, where XRD analysis of processed GGBS shows that the high amounts of quartz and silica oxide are more than cinder.

\subsection{Physical properties}

The cinder's specific surface area is observed as 218.20 $\mathrm{m}^{2} / \mathrm{kg}$, which is also within the range of 178 to $379 \mathrm{~m}^{2} / \mathrm{kg}$ specific surface area of steel slag (Humbert and Castro-Gomes 2019). The specific surface area plays a vital role in achieving the ultimate strength and water demand to produce a consistent mix. The cinder's specific gravity is between 2.60 to 2.65 , and the residue available in the cinder is near about 2 to $3 \%$.

The specific surface area of processed GGBS is observed around 700 to $800 \mathrm{~m}^{2} / \mathrm{kg}$ and is genuinely fine (Teng et al. 2013). The specific surface area plays a vital role in achieving the ultimate strength and water demand to produce a consistent mix. The specific gravity of processed GGBS is between 2.70 to 2.85 , and the residue available in the cinder is near about 2 to $3 \%$. Since the cinder's composition is almost nearer to steel slag, it is not acceptable to utilize the cinder in the concrete industry. The current research scenario of cinder search on the internet by keywords like cinder, cinder in construction industries, cinder in concrete and cinder, and cement but unable to substantial literature or research impact. Then, the experimental confirmation is needed to investigate the possible use of cinder at the laboratory level. Also, try to find a current utilization scenario from a supplier; they inform that the clinker production used in cement production means a change in primary raw material for cement. The preliminary research is carried out on cinder and processed GGBS with dry sieving, consistency, setting time, soundness, Blaine air permeability, compressive strength, and pozzolanic reactivity to investigate the possibilities of utilization as SCMs.

\section{Experimental methodology}

The experimental studies include numerous testing methodologies to check the cement and binder properties when SCMs were used as a partial replacement according to the relevant Indian Standard (IS 1727 2013); out of those different tests following tests were performed to check the pozzolanic reactivity of particular SCMs with cement. The microstructural study was also conducted to know about Ettringite, $\mathrm{CSH}$ gel, and Portlandite formation.

\subsection{Residue available}

To determine the percentage residue available in the different blend according to Part 1 of Indian Standard 4031 (IS 4031-1 2016), agitate the cement sample to be examined by shaking for 2 minutes in a stoppered jar to disperse agglomerates. After 2 minutes, keep it to stir the resulting powder and then take out the sample. After completing shaking, weigh the material on the weighing balance machine with $0.01 \mathrm{gm}$. accuracy and calculate the residue percentage for that sample.

\subsection{Density}

To determine the density of different blends according to Part 11 of Indian Standard 4031 (IS 4031-11 2013), the Le Chetelier flask was used. According to the above standard, for this test it is advisable to use kerosene free of water or naphtha with specific gravity not less than 0.7313 . Fill the flask with kerosene or naphtha up to the mark 0 to 1 , take the 60 to 64 grams of the sample, and pour in a flask, taking care to prevent material from sticking at the neck of the flask. The final reading shall be taken after the flask has been immersed in a water bath. Then, take the final reading, calculate the difference between the final and initial reading and weight of the sample, and calculate the sample's density. It does not show the blend's quality, but it is useful to calculate the binder's absolute volume in the mix design.

\subsection{Fineness}

To determine the specific surface area of different prepared blends (IS 4031-2 2013), this has an essential role in the heat of hydration; in general, the strength directly proportional to the specific surface area of a material. It also plays a crucial role in early age strength. Here, all the tests conducted considering constant for OPC. The fineness of cement or binder plays enough roles to gain early age strength and affect the setting time of cement.

\subsection{Standard consistency}

To determine the quantity of water required to produce cement paste is known as standard consistency of cement (IS 4031-4 2019). It is also useful to calculate the water content for the initial and final setting time test, soundness, and compressive strength test, so it is a prerequisite test for these tests.

\subsection{Soundness}

This test performed different autoclave and Le Chetelier methods to determine the material's soundness (IS 4031-3 2019). The Le Chetelier method was adopted for the present study. The cement or binder paste is prepared with $0.78 \mathrm{P} \%$ water content, where $\mathrm{P}$ is the standard consistency of cement paste. During filling of mould, do not give extra pressure to fill material after filling the mould with a glass plate with the top and bottom sides. This filled mould was kept in the immersed condition in the water at a temperature of $27 \pm 2^{\circ} \mathrm{C}$ for 24 hours. After 24 hours, take out from the water, take the initial reading between two indicators, put it in a water bath for 3 hours under boiling water, and then take the final reading between two indicators. Calculate the soundness based on initial and final reading for that sample.

\subsection{Setting time}

Initial and final setting time show that taken time for 
hydration of cement or cement with SCMs to initial set and final set (IS 4031-5 2019). The Vicat apparatus is used to measure the setting time of cement. The test procedure of setting time is divided into three different parts as sample preparation, initial setting time, and final setting time. In sample preparation, the sample cement paste was prepared with cement and water. The take water required to cement paste is 85 percent of standard consistency. The prepared cement paste was filled into the Vicat mould in a specified manner within 3 to 5 minutes. Lapsed time was measured with a stopwatch at the moment water was added into the cement. The time elapsed between when the water is added to the cement and when the needle penetrates the test sample to a depth equal to 33 to $35 \mathrm{~mm}$ from the top is taken as initial setting time. Similarly, the time elapsed between when the water is added to the cement and when the plunger makes an impression on the test block top is taken as the final setting time.

\subsection{Compressive strength and pozzolanic reac- tivity}

The specimen was prepared according to IS 1727 (2013) to determine the compressive strength of different prepared blends. The mortar composition contains one part of cement, three-part of standard sand (IS 650 2018), and the water content for that particular mix $\mathrm{P} / 4+3 \%$. The prepared sample is mixed with a mechanically operated mortar mixing machine. The produced specimen warped in a damp cloth for 24 hours and then de-moulded immersed in water at the temperature $27 \pm 2^{\circ} \mathrm{C}$.

\subsection{XRD analysis}

$\mathrm{X}$-ray diffraction, which is used to analyze the crystalline structure and morphology of the material is usually known as XRD analysis or XRD test, is a non-destructive test to evaluate the material's internal formation. By method for investigating the gem structure, XRD examination is utilized to recognize the crystalline stages present in a material and uncover substance organization data. Distinguishing proof of stages is accomplished by correlating the obtained information to that in reference databases (Arandigoyen and Alvarez 2007). X-ray diffraction is valuable for examining minerals, polymers, erosion items, and obscure materials. To a large extent, the examples examined on the element are broken down by powder disintegration, using tests arranged as fine ground powder. In general, the hardened cement paste consists of Ettringite 15 to $20 \%$, Tobermorite (CSH gel) 50 to $60 \%$, Portlandite (calcium hydroxide) 20 to $25 \%$, and voids 5 to $6 \%$ (Kosmatka et al. 2011; Mamlouk and Zaniewski 2011).

Nevertheless, the XRD analysis was executed on the mortar powder sample extracted from the sample cured in normal water for 28 days. The powered sample examined using XRD with $\mathrm{Cu}-\mathrm{K} \alpha$ radiation. The samples were analyzed from $0^{\circ}$ to $80^{\circ}(2 \theta)$ to get the XRD pattern. Phase identification was carried out using a reference database crystallography open database (COD), available with Match 3.

\subsection{Fourier transform infrared spectroscopy (FTIR)}

The mortar powder samples used for SEM images and XRD tests were used to get infrared spectra using the Shimadzu spectrometer (Model 8400S, Tokyo). The KBr pellet technique was incorporated to obtain the FTIR results. The scans were performed in the transmittance range of 4000 to $500 \mathrm{~cm}^{-1}$.

\section{Experimental results}

\subsection{Residue available}

Figure 3 shows the residue results available in different prepared blends with cinder and processed GGBS, comparing them with OPC. The available residue results were observed in the range of $2.07 \%$ to $3.01 \%$, fulfilling the threshold limit $(10 \%)$ for residue available in the binder (IS 4031-1 2016).

\subsection{Density}

In the present study, the observed density of OPC, cinder, and processed GGBS were 3.14, 2.62, and 2.84. Figure 4 shows the density of different prepared blends with cinder and processed GGBS and compare with OPC. It is useful to calculate the absolute volume of the binder in the mix design. The results show that the density decreases when the percentage of replaced cement was increased by cinder (density 3.14 to 2.69 ) or processed GGBS (density 3.14 to 2.96 ) additions. The decrement of specific gravity may need a higher amount of water to get better workability in concrete.

\subsection{Fineness}

Figure 5 shows the fineness of different prepared blends with cinder and processed GGBS compared with OPC. The fineness of cement or binder is measured by the particle size in terms of specific surface area, expressed in $\mathrm{m}^{2} / \mathrm{kg}$, determined by Blaine air permeability method

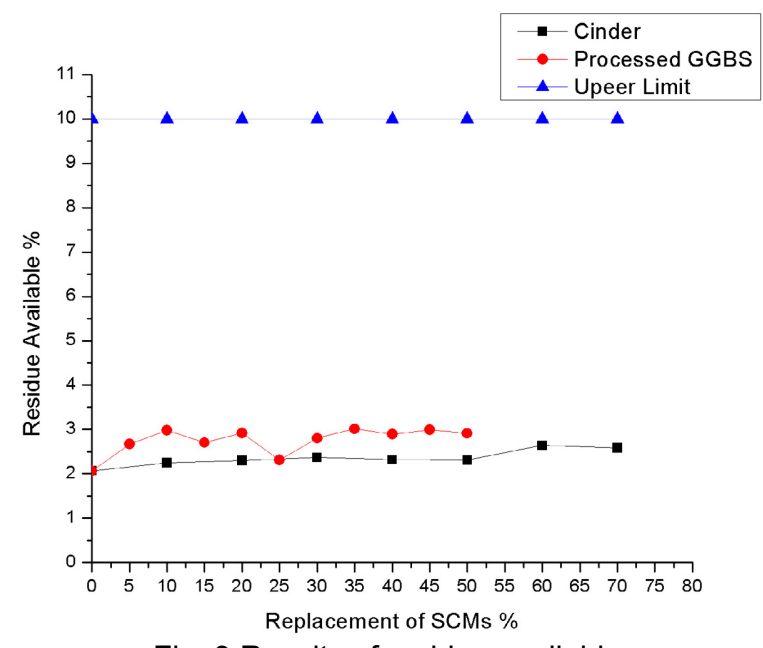

Fig. 3 Results of residue available. 
as specified in Indian Standard IS 1489, Part 2 (IS 1489-2 2015). The utilization of cinder and processed GGBS shows different effects from each other. Cinder $(218.20$ $\mathrm{m}^{2} / \mathrm{kg}$ ) had less specific surface area than processed GGBS $\left(851.28 \mathrm{~m}^{2} / \mathrm{kg}\right)$. The utilization of cinder reduces the specific surface area of prepared blends, while the processed GGBS increases the specific surface area. However, the increase in surface area with processed GGBS is significant at $50 \%$ replacement of cement. Figure 6 shows the compressive strength of blends made up with cinder at an early age and the corresponding specific surface area. Thus, the higher replacement level of cement by cinder shows decrement in the prepared blend's specific surface area and early age strength. Similarly, Fig. 7 shows the compressive strength of blends made up with processed GGBS at an early age and the corresponding specific surface area of that blend. In this way, the higher replacement level of processed GGBS shows an increment in the specific surface area of prepared blends and early age strength.

\subsection{Standard consistency}

Figure 8 shows the standard consistency results prepared different blends with cinder and processed GGBS and compare with OPC. The general acceptance criteria of

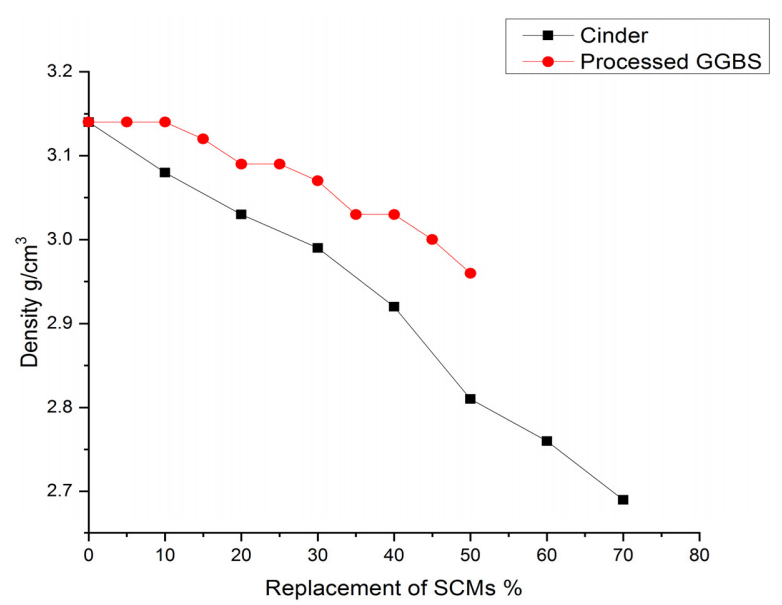

Fig. 4 Results of density.

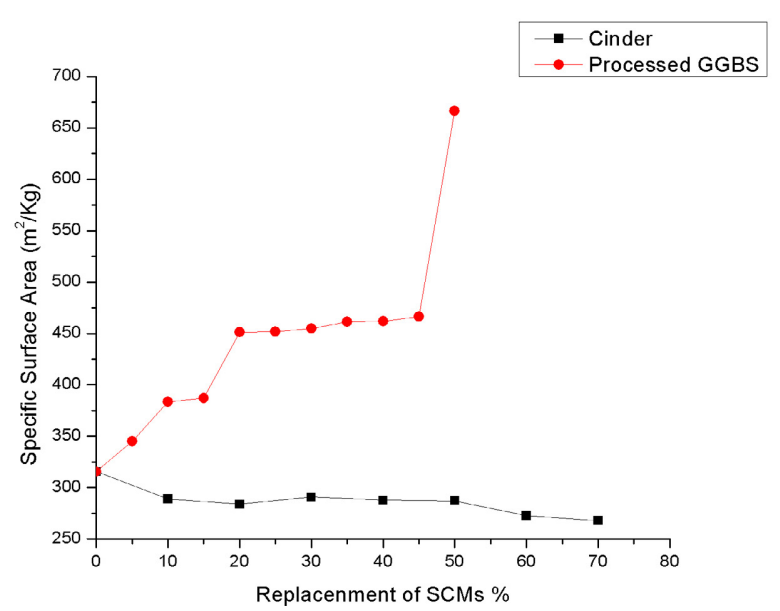

Fig. 5 Results of fineness by Blaine air permeability. standard consistency are $26 \%$ to $33 \%$. In the present study, the results show that the water demand of binder increases with replacement level of SCMs increases because the increase in fineness of the binder also increases with higher percentage replacement of SCMs.

\subsection{Soundness}

Figure 9 shows the soundness of different prepared blends with cinder and processed GGBS compared with OPC. In this present study, the soundness was measured by Le Chetelier method. The potential volume expansion of cement or binder is induced because of the reaction of free lime, magnesium oxides, and present alkali content in different cement or binder (Rezaee et al. 2019). In the present study, cement and binder soundness between 1 to $3 \mathrm{~mm}$ is less than the threshold limit of soundness, 10 mm for cement (IS 4031-3 2019).

\subsection{Setting time}

Initial and final setting time show that taken time for hydration of cement or cement with SCMs to initial set and final set (IS 4031-5 2019). Figure 10 shows the initial and final setting times of different prepared blends

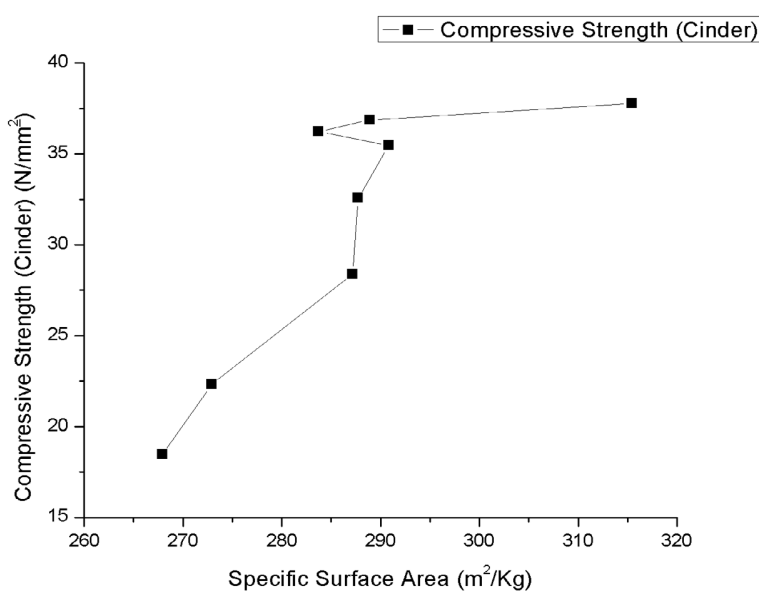

Fig. 6 Results of compressive strength at 7 days for different fineness (cinder).

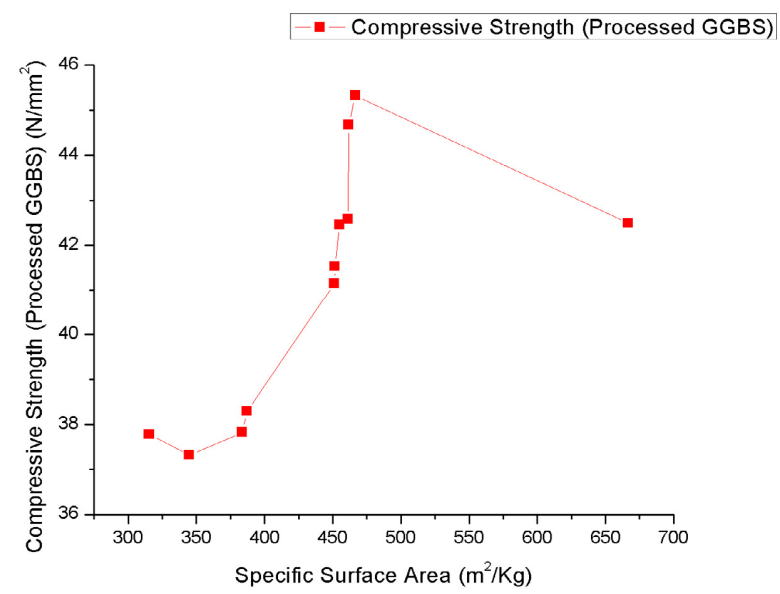

Fig. 7 Results of compressive strength at 7 days for different fineness (processed GGBS). 
with cinder and processed GGBS compared with OPC. The incorporation of cinder and processed GGBS decreases the initial and final set up to $50 \%$ and $25 \%$. After that much replacement, slight changes were observed in initial and final setting time, but different blends were fulfilling the required criteria for OPC. Thus, the replacement of OPC by cinder and processed GGBS may beneficial for speedy construction practice because of the lower value of the initial and final setting time of different binders.

\subsection{Compressive strength and pozzolanic reac- tivity}

Figures 11 and 12 show the compressive strength and pozzolanic index of different prepared blends with cinder and processed GGBS, respectively, and compare with OPC. In the present study, the result of compressive strength shows decrement with cement replacement by cinder. However, in another way, the results of processed GGBS quite good compare to the result of cinder. The criteria of acceptable results are $85 \%$ results of cement's compressive strength (IS 1727 2013). According to this, the replacement of cement by cinder and processed GGBS is possible up to $50 \%$. The results were compared with the result of OPC.

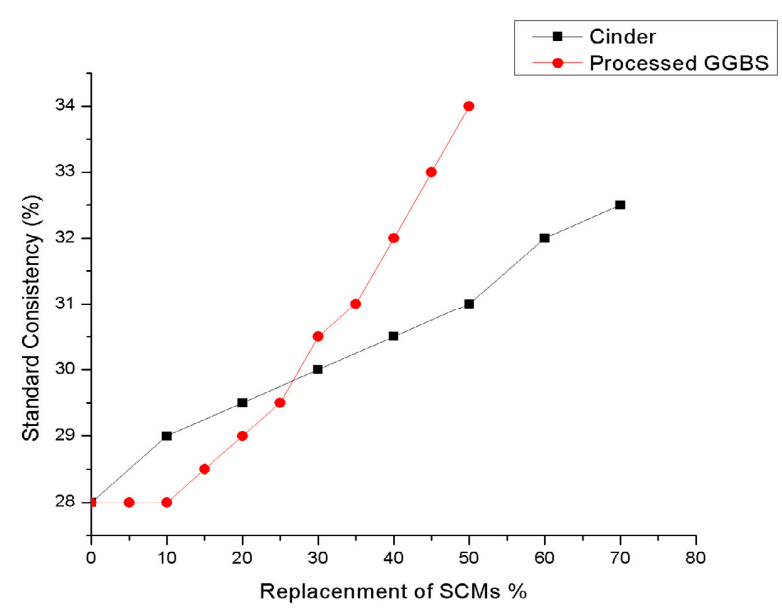

Fig. 8 Results of standard consistency.

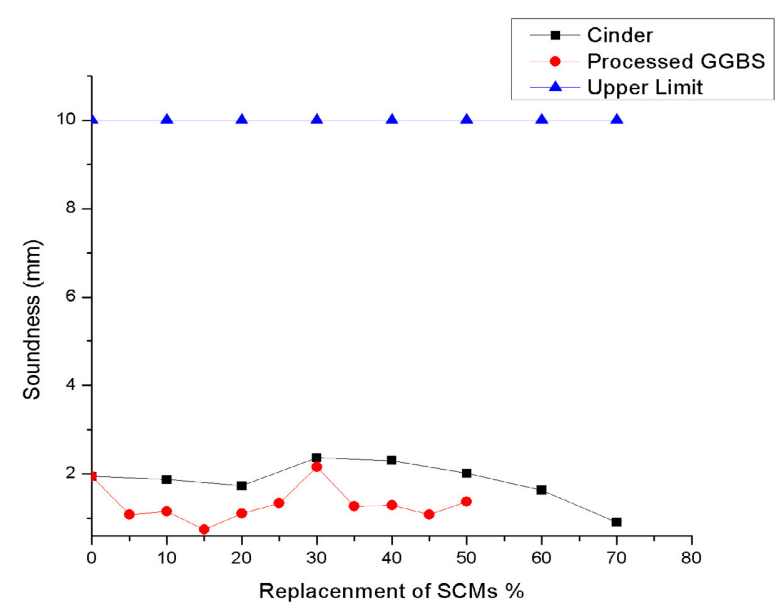

Fig. 9 Results of soundness.

\section{Discussion on experimental results}

SCMs contain residue themselves, but it is necessary to determine the percentage residue available in the different blends prepared with SCMs. The results show that the SCMs do not contain more residues, so the overall prepared blend has available residue less than the permissible limit.

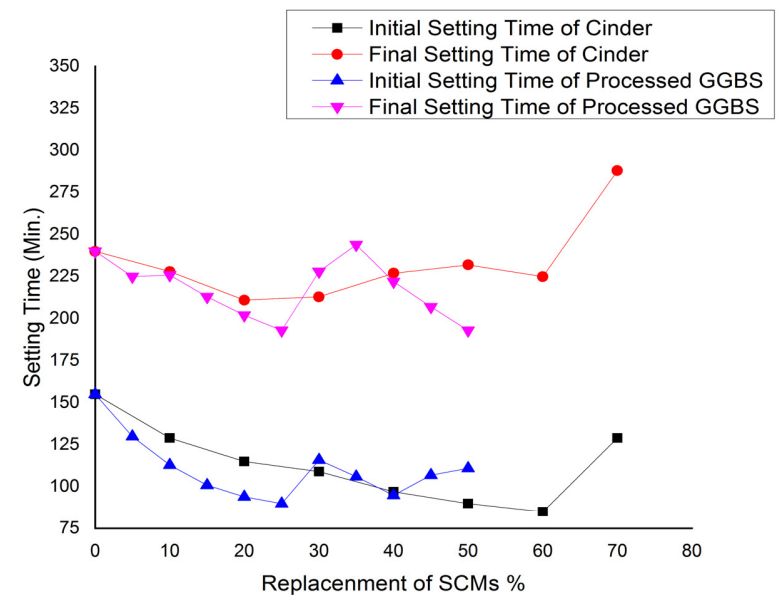

Fig. 10 Results of setting time.

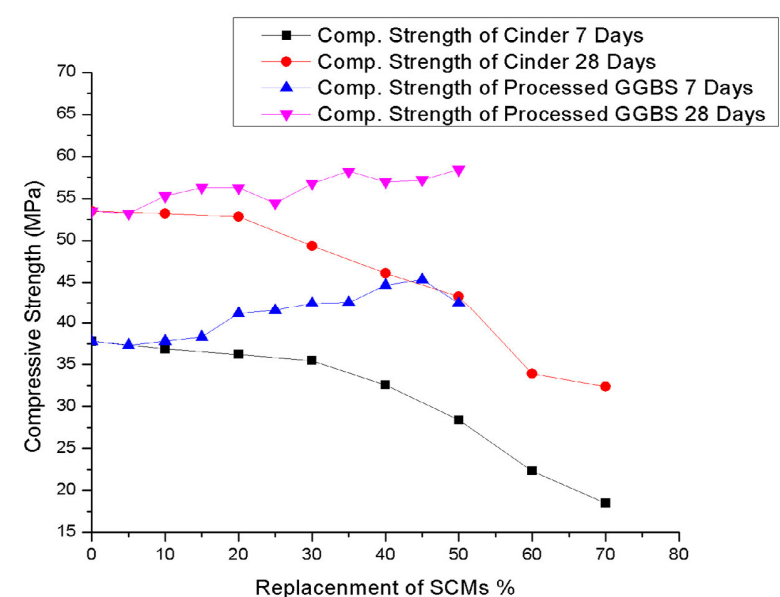

Fig. 11 Results of compressive strength.

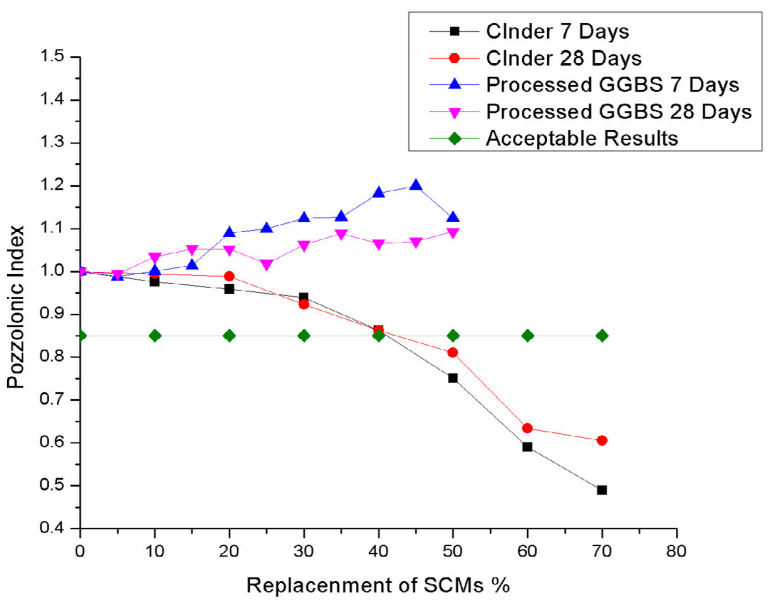

Fig. 12 Results of Pozzolanic Index. 
Table 2 Presence of different match phases (\%) in XRD analysis.

\begin{tabular}{cccc}
\hline Specimen & $*$ OPC (\%) & $* \mathbf{C 4 0}(\mathbf{\%})$ & $* \mathbf{M 4 0}(\mathbf{\%})$ \\
\hline Tobermorite $(\mathbf{C S H}$ gel) & 68.1 & 49.3 & 50.5 \\
Ettringite & 22.8 & 37.2 & 30.2 \\
Calcite $\left(\mathbf{C a C O}_{3}\right)$ & 5.2 & 11.7 & 10.5 \\
Portlandite & 3.9 & 1.8 & 8.7 \\
\hline
\end{tabular}

*Match phases are shown as percentages

Specific gravity is nothing but the ratio between the binder's weight and the medium's equal volume. The standard specific gravity of OPC is around 3.14. In present studies, specific gravity is initially nearer to OPC, but then after increment of SCMs shows decrement in specific gravity.

The specific surface area increases with cement fineness and gives a higher opportunity to hydration's chemical reaction heat. The compressive strength is directly proportional to the specific surface area (Ganesan et al. 2007). It also plays a vital role in early age strength. Here, all the tests conducted considering constant for OPC. The fineness of cement or binder plays a vital role in gaining early age strength and affecting the setting time of cement. The fineness of cement or binder has measured particle size in terms of specific surface area, expressed in $\mathrm{m}^{2} / \mathrm{kg}$, calculated by particle size analyzer or Blaine air permeability method, which, among available methods, is more suitable because of cement's smaller particle size.

The specific surface area increases with cement fineness and gives a higher chemical reaction (Ganesan et al. 2007). The chemical reaction gives a better possibility of the heat of hydration, leading to early-age strength development but not that much contribute in ultimate strength.

Consistency, the quantity of water required to produce cement paste, and the percentage of water required to produce the same are known as standard consistency of cement or binder (IS 4031-4 2019). This test is also critical because after identifying the standard consistency, further tests can be conducted like the soundness test, the initial setting, and final setting time and compressive strength of cement or binder. In this way, it is a pre-requisite test.

It is necessary to determine the reaction amount of pozzolanic minerals with calcium hydroxide in a humid environment (Yücel and Özcan 2019). However, the cinder and processed GGBS are used in this study as pozzolanic material. A pozzolanic reactivity test was conducted to get an idea about cinder and processed GGBS usability. The compressive strength of cement or binder is essential for identifying the possibility of replacement level of cinder and processed GGBS in cement. This test is also useful for cement paste in a mix design and shows cement and binder quality.

The compressive strength results of different blends are plotted in Fig. 11, which shows the replacement of cinder and processed GGBS gives acceptable results up to $40 \%$ acceptable results among all different blends. The tricalcium silicate (alite) is hydrated to produce calcium silicate hydrates, lime, and heat. CSH has a short-networked fiber structure that contributes significantly to the cement mortar's initial strength (Kosmatka et al. 2011; Mamlouk and Zaniewski 2011).

The amount of voids is higher in cinder $40 \%$ (C40) than control specimen (OPC) and processed GGBS $40 \%$ (M40) at 7 and 28 days, which may lead to lower compressive strength that happened in compressive strength of C40 is lower compared to OPC and M40. The presence of fibrous $\mathrm{CSH}$ in the form of needles (Abdelrazig et al. 1989) was observed in all samples at 7 days of curing. However, further, it converted to the mesh form of $\mathrm{CSH}$; also, with this pozzolanic reaction, calcium hydroxide (Portlandite) was formed in the shape cubical form hexagonal plates (Abdelrazig et al. 1989; Mehta and Monteiro 2017), which was observed in both the curing age. It shows that the material matrices become homogeneous, flat, and dense with increased curing age.

The XRD analysis shows that change occurred in the formation of CSH gel, Ettringite, calcite, and Portlandite. The CSH gel contributes to the strength of the cement paste. The reaction of $\mathrm{CSH}$ gel generates less heat and proceeds at a slower rate. The contribution of di-calcium silicate $\left(\mathrm{C}_{2} \mathrm{~S}\right)$ in initial strength is slow and responsible for long-term strength (Mamlouk and Zaniewski 2011). As per Table 2, the amount of Tobermorite ( $\mathrm{CSH}$ gel) is less in C40, and M40 than the OPC but nearer to OPC, so partial replacement is possible. Similarly, the Portlandite amount shows significant changes in C40 and M40, as shown in Table 2. The amount of Portlandite is decreases in C40, but it increases in M40. The higher amount of Portlandite in M40 leads to high compressive strength and, lower Portlandite causes a decrement in compressive strength.

The XRD patterns of the control specimen (OPC), cinder (C40) and processed GGBS (M40) that were cured in normal water for 28 days with samples being collected from a depth of $30 \mathrm{~mm}$ from the sample surface are shown in Figs. 13, 14 and 15, respectively. Tri-calcium silicate $\left(\mathrm{C}_{3} \mathrm{~S}\right)$ reacts with gypsum in the presence of water and generates the Ettringite and heat. In which Ettringite contains long crystals. These crystals are only stable in solution with gypsum (Kosmatka et al. 2011; Mamlouk and Zaniewski 2011). The XRD patterns of OPC, C40 and M40 specimens cured in normal water showed prominent peaks of Ettringite in OPC at $2 \theta$ values of $34.47^{\circ}, 40.66^{\circ}$, and $46.14^{\circ}, \mathrm{C} 40$ at $2 \theta$ values of $36.93^{\circ}$ and $40.72^{\circ}$, and for M40 at $2 \theta$ values of $27.44^{\circ}$, $37.03^{\circ}$, and $50.34^{\circ}$. The tricalcium silicate (alite) is hy- 
drated to produce Tobermorite (calcium silicate hydrates - CSH gel), lime, and heat. The CSH gel has a short-networked fiber structure that contributes significantly to the cement's initial strength (Kosmatka et al. 2011; Mamlouk and Zaniewski 2011). The presence of Tobermorite (CSH gel) in an amorphous form as a premium hydration product is indicated by a wide dispersion ring around $2 \theta$ values of $18.44^{\circ}, 36.96^{\circ}$, and $50.46^{\circ}$ for OPC, $2 \theta$ values of $26.57^{\circ}, 39.91^{\circ}$, and $55.15^{\circ}$ for $\mathrm{C} 40$ and M40 at $2 \theta$ values of $26.76^{\circ}, 37.02^{\circ}$, and $50.50^{\circ}$.

The XRD patterns of OPC, C40 and M40 specimens cured in normal water showed prominent peaks of Portlandite in $\mathrm{OPC}$ at $2 \theta$ values of $55.74^{\circ}, 64.33^{\circ}$, and $68.07^{\circ}$, $\mathrm{C} 40$ at $2 \theta$ values of $55.75^{\circ}, 64.46^{\circ}$, and $67.96^{\circ}$ and for M40 at $2 \theta$ values of $46.27^{\circ}, 55.83^{\circ}$, and $60.37^{\circ}$. The XRD spectra show that the Portlandite peaks' intensities were lower for samples M40 than OPC and C40. The Portlandite attributes significantly in the formation of
$\mathrm{CaCO}_{3}$ (Ramesh and Kondraivendhan 2020). The XRD patterns showed prominent peaks of calcite $\left(\mathrm{CaCO}_{3}\right)$ in $\mathrm{OPC}$ at $2 \theta$ values of $42.81^{\circ}, 60.29^{\circ}$, and $68.07^{\circ}$. Similarly in $\mathrm{C} 40$ at $2 \theta$ values of $42.87^{\circ}, 60.37^{\circ}$, and $64.46^{\circ}$, and for M40 at $2 \theta$ values of $50.5^{\circ}$ and $64.34^{\circ}$. The XRD patterns of OPC, C40 and M40 specimens cured in normal water showed ambient peaks of quartz are evident at $2 \theta$ values of $21.24^{\circ}$ and $27.04^{\circ}, 2 \theta$ values of $21.30^{\circ}$ and $27.03^{\circ}$ in $\mathrm{C} 40$, and $2 \theta$ values of $21.38^{\circ}$, and $27.11^{\circ}$, which correspond with the presence of fine aggregate traces in the mortar powder (Ramesh and Kondraivendhan 2020).

The FTIR spectrum of the OPC, C40, and M40, as shown in Fig. 16, shows a loud band at $3630 \mathrm{~cm}^{-1}$ to 3640 $\mathrm{cm}^{-1}$ strongly associated with $\mathrm{O}-\mathrm{H}$ stretching vibrations of Portlandite $\left[\mathrm{Ca}(\mathrm{OH})_{2}\right]$ (Horgnies et al. 2013). The carbonates $\left(\mathrm{CaCO}_{3}\right)$ peaks at $2510 \mathrm{~cm}^{-1}$ to $2520 \mathrm{~cm}^{-1}$ (weak stretching), $1411 \mathrm{~cm}^{-1}$ to $1450 \mathrm{~cm}^{-1}$ (strong

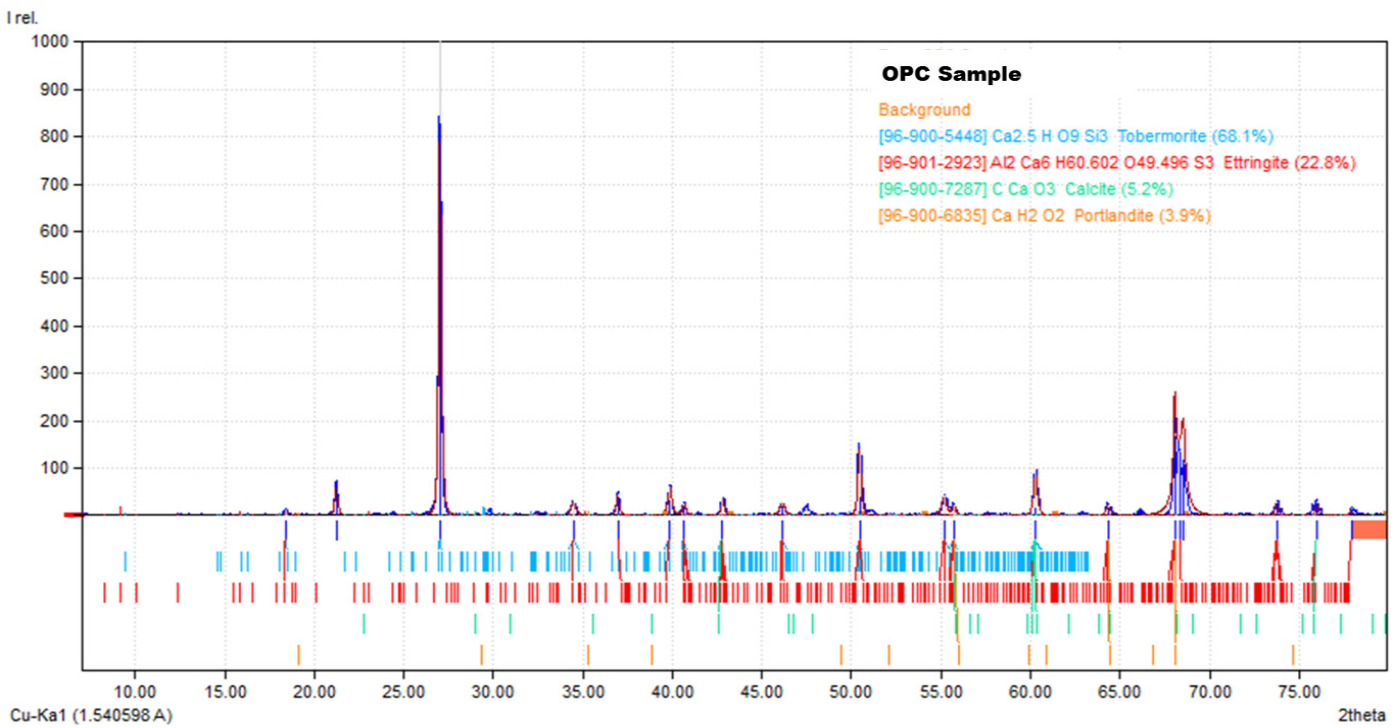

Fig. 13 X-ray diffraction pattern of OPC at 28 days.

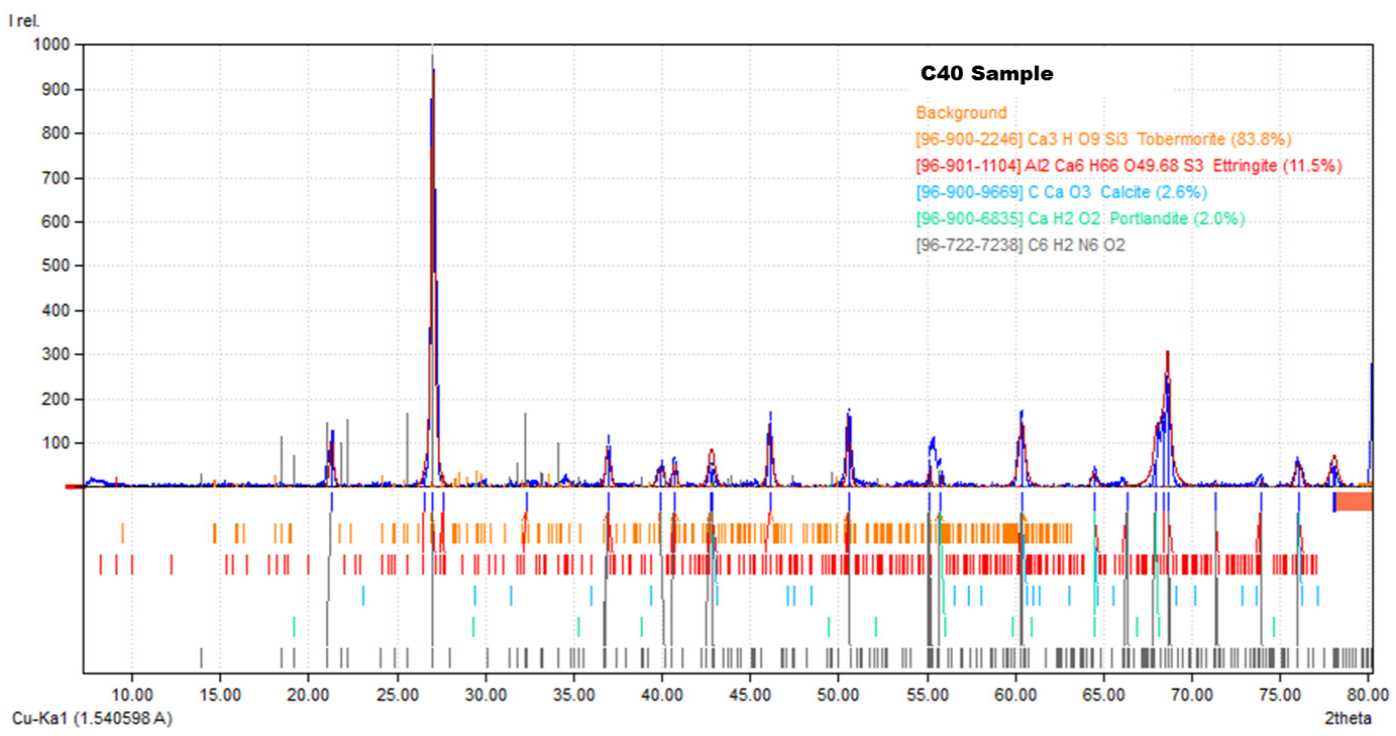

Fig. 14 X-ray diffraction pattern of C40 at 28 days. 
stretching), $860 \mathrm{~cm}^{-1}$ to $880 \mathrm{~cm}^{-1}$ (medium stretching) and $690 \mathrm{~cm}^{-1}$ to $740 \mathrm{~cm}^{-1}$ (strong stretching) are observed due to the reactions of atmospheric $\mathrm{CO}_{2}$ with calcium hydroxide. In calcium silicate hydrates $(\mathrm{CSH})$ gel formation, the strong band at $960 \mathrm{~cm}^{-1}$ to $980 \mathrm{~cm}^{-1}$ is due to Si-O asymmetric stretching vibration of $\mathrm{C}_{3} \mathrm{~S} \quad \mathrm{C}_{2} \mathrm{~S}$ (Horgnies et al. 2013; Kupwade-Patil et al. 2018). Out of plane, Si-O bending and in-plane Si-O bending are observed at $515 \mathrm{~cm}^{-1}$ to $525 \mathrm{~cm}^{-1}$ (strong stretching) and $440 \mathrm{~cm}^{-1}$ to $480 \mathrm{~cm}^{-1}$ (strong stretching), respectively (Horgnies et al. 2013; Kupwade-Patil et al. 2018). The formation of calcium aluminosilicate hydrates (CASH gel) possible because of the higher amount of alumina present in a processed GGBS (Kupwade-Patil et al. 2018). The alumina reacts with CSH gel and converts it into CASH gel. The peaks of shifted CASH gel was from
$960 \mathrm{~cm}^{-1}$ to $1160 \mathrm{~cm}^{-1}$. The replacement of alumina forming CASH structures from a precursor of Al-Tobermorite was designed. It is possible because of the natural aluminosilicates' reaction in the presence of processed GGBS (Kupwade-Patil et al. 2018).

\section{Analytical technique}

The experimental results show that cinder and processed GGBS replacement is possible by up to $50 \%$. However, it is difficult to find an optimum solution based on various properties checked as per the experimental program. Multi-criteria decision making (MCDM) is most useful in such kind of situation. Many methods are available for MCDM, but there is a technique for order performance by similarity to ideal solution (TOPSIS) useful to find out

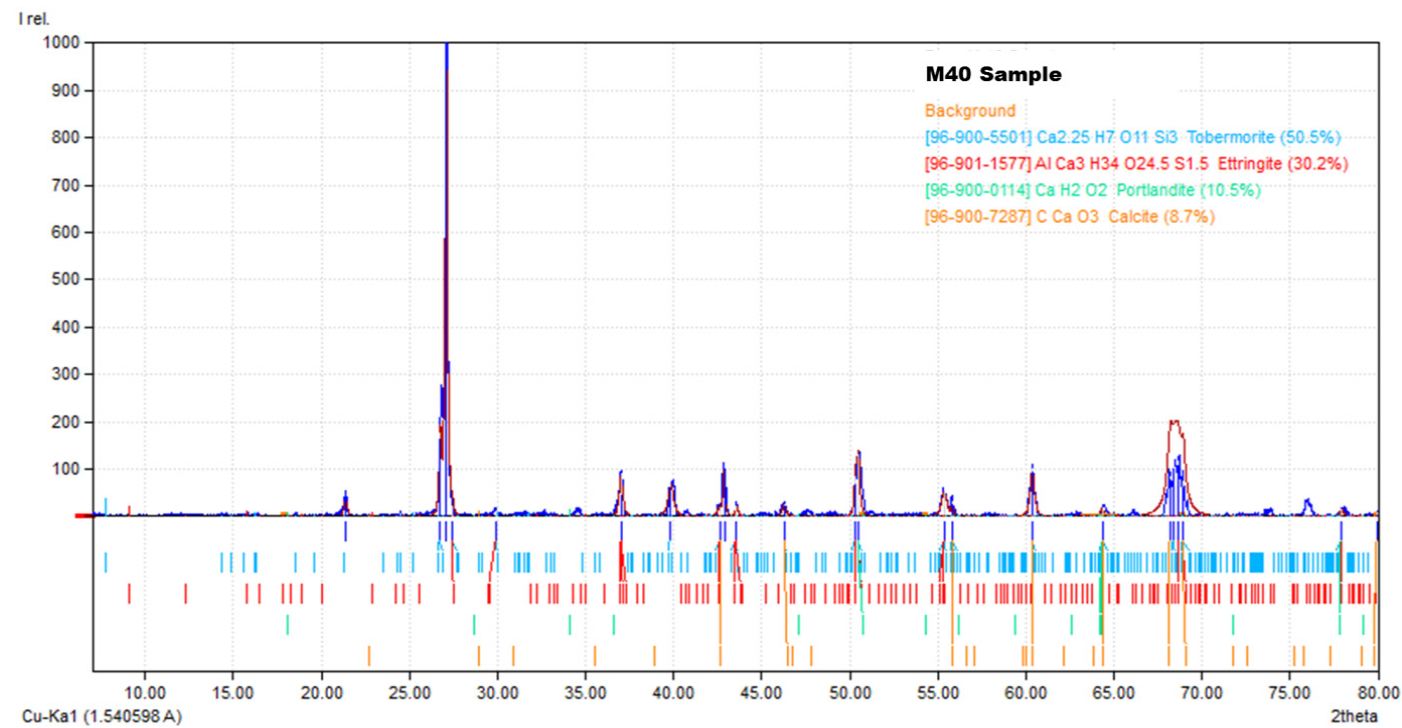

Fig. 15 X-ray diffraction pattern of M40 at 28 days.

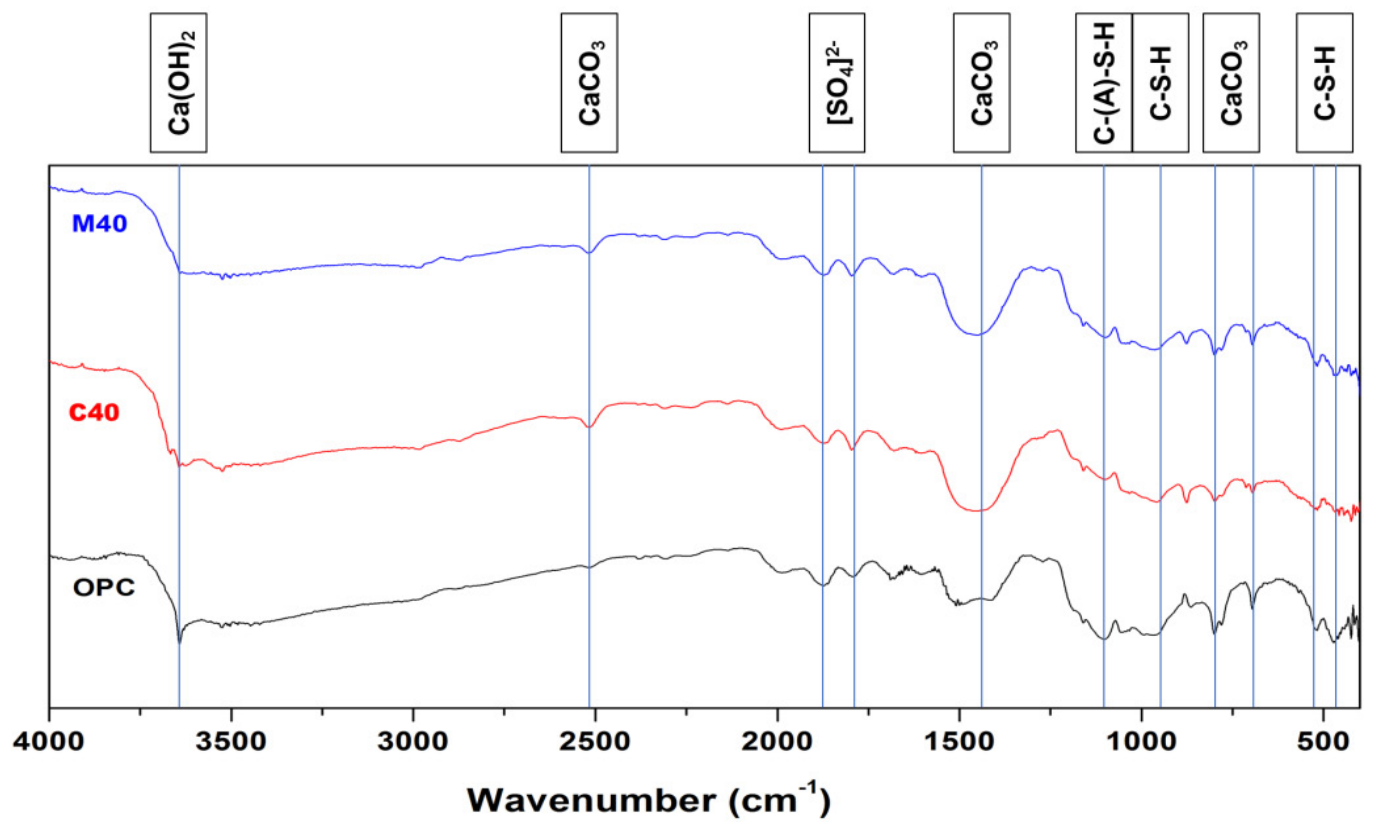

Fig. 16 FTIR analysis of OPC, C40, and M40 at 28 days. 
Table 3 Selected attributes and their weights based on entropy method.

\begin{tabular}{ll}
\hline \multicolumn{1}{c}{ Properties } & \multicolumn{1}{c}{ Justification } \\
\hline Specific gravity (0.11) & To reduce the voids and increase particle packing density. \\
Blaine air permeability (0.11) & The specific surface area plays a vital role in compressive strength \\
Initial setting time (0.25) & Available oxides in SCMs may change the initial setting time. \\
Compressive strength 07 days (0.31) & Early age strength at 7 days necessary as stipulated in Indian Standard (IS 1727 2013) \\
Compressive strength 28 days (0.23) & $85 \%$ of ultimate strength at 28 days necessary as stipulated in Indian Standard (IS \\
& 1727 2013) \\
\hline
\end{tabular}

Table 4 Normalized matrix for cinder.

\begin{tabular}{cccccc}
\hline Samples & $\begin{array}{c}\text { Specific } \\
\text { gravity }\end{array}$ & $\begin{array}{c}\text { Blaine air per- } \\
\text { meability }\end{array}$ & Initial setting time & $\begin{array}{c}\text { Compressive strength } 7 \\
\text { Compressive strength 28 } \\
\text { days }\end{array}$ \\
\hline $\mathbf{0}$ & 0.38 & 0.39 & 0.47 & 0.42 & 0.41 \\
$\mathbf{1 0}$ & 0.37 & 0.36 & 0.39 & 0.40 & 0.41 \\
$\mathbf{2 0}$ & 0.37 & 0.35 & 0.35 & 0.40 & 0.40 \\
$\mathbf{3 0}$ & 0.36 & 0.36 & 0.33 & 0.36 & 0.32 \\
$\mathbf{4 0}$ & 0.35 & 0.35 & 0.30 & 0.25 & 0.33 \\
$\mathbf{5 0}$ & 0.34 & 0.35 & 0.26 & 0.21 \\
\hline
\end{tabular}

Table 5. Normalized matrix for processed GGBS.

\begin{tabular}{cccccc}
\hline Samples & $\begin{array}{c}\text { Specific } \\
\text { gravity }\end{array}$ & $\begin{array}{c}\text { Blaine air } \\
\text { permeability }\end{array}$ & $\begin{array}{c}\text { Initial setting time } \\
\text { Compressive strength } \\
\text { days }\end{array}$ & $\begin{array}{c}\text { Compressive strength } \\
\text { 28 days }\end{array}$ \\
\hline $\mathbf{0}$ & 0.31 & 0.21 & 0.42 & 0.28 & 0.29 \\
$\mathbf{5}$ & 0.31 & 0.23 & 0.35 & 0.28 & 0.29 \\
$\mathbf{1 0}$ & 0.31 & 0.26 & 0.30 & 0.28 & 0.30 \\
$\mathbf{1 5}$ & 0.31 & 0.26 & 0.27 & 0.30 & 0.30 \\
$\mathbf{2 0}$ & 0.30 & 0.30 & 0.25 & 0.31 & 0.29 \\
$\mathbf{2 5}$ & 0.30 & 0.30 & 0.24 & 0.31 & 0.31 \\
$\mathbf{3 0}$ & 0.30 & 0.31 & 0.31 & 0.33 \\
$\mathbf{3 5}$ & 0.30 & 0.31 & 0.29 & 0.33 \\
$\mathbf{4 0}$ & 0.30 & 0.31 & 0.26 & 0.31 \\
$\mathbf{4 5}$ & 0.29 & 0.31 & 0.29 & 0.31 \\
\hline
\end{tabular}

the optimum solution or best alternative among all prepared blends (Rashid et al. 2018). TOPSIS gives the solution based on the positive ideal solution and the negative ideal solution and the weights of attributes calculated for the entropy method. The entropy method was proposed by Shannon and Weaver (1947) and highlighted by Zeleny (1982) and Rao (2013). The selected attributes are specific gravity, Blaine air permeability, initial setting time, compressive strength at 7 and 28 days, and other attributes. Their weights are as shown in Table 3.

\section{Techniques for order performance by similarity to ideal solution method}

The steps in the TOPSIS method are explained below.

Step 1: Find the beneficial and non-beneficial criteria for the requirement and then create an evaluation of matrix " $E$ " for the " $m$ " alternative and for " $n$ " criteria based on Eq. (1) below.

$$
E=\left[X_{i j}\right]_{m \times n}
$$

Step 2: Calculate E Matrix's normalization, $\mathrm{R}_{\mathrm{ij}}$ based on Eq. (2), for cinder and processed GGBS normalized matrices, as given in the following Tables $\mathbf{4}$ and $\mathbf{5}$.

$$
R_{i j}=\frac{X_{i j}}{\sqrt{\sum_{i=1}^{m} X_{i j}^{2}}}
$$

Step 3: Calculate the weighted normalized matrix based on Eq. (3). The weighted normalized matrixes were calculated based on those given in Tables 6 and 7 for cinder and processed GGBS.

$$
V_{i j}=W_{j} \times R_{i j}
$$

Step 4: Find out the positive ideal solution and negative ideal solution based on the weighted normalized matrixes based on Eqs. (4) and (5). The positive ideal solution and negative ideal solution for cinder and processed GGBS are shown in Tables 8 and 9.

$$
\begin{aligned}
V^{+} & =\left\{\left(\sum_{i}^{M a x} \frac{V_{i j}}{j \in J}\right),\left(\sum_{i}^{M i n} \frac{V_{i j}}{j \in J}\right), i=1,2, \ldots, m\right\} \\
& =\left\{V_{1}^{+}, V_{2}^{+}, V_{3}^{+}, \ldots, V_{m}^{+}\right\}
\end{aligned}
$$


Table 6 Weighted normalized matrix for cinder.

\begin{tabular}{cccccc}
\hline Samples & $\begin{array}{c}\text { Specific } \\
\text { gravity }\end{array}$ & $\begin{array}{c}\text { Blaine air } \\
\text { permeability }\end{array}$ & Initial setting time & $\begin{array}{c}\text { Compressive strength } \\
\text { 7 days }\end{array}$ & $\begin{array}{c}\text { Compressive strength } \\
\text { 28 days }\end{array}$ \\
\hline $\mathbf{0}$ & 0.0415 & 0.0431 & 0.1171 & 0.1288 & 0.0923 \\
$\mathbf{1 0}$ & 0.0407 & 0.0395 & 0.0975 & 0.1257 & 0.0919 \\
$\mathbf{2 0}$ & 0.0401 & 0.0388 & 0.0869 & 0.1235 & 0.0912 \\
$\mathbf{3 0}$ & 0.0395 & 0.0398 & 0.0824 & 0.1209 & 0.0852 \\
$\mathbf{4 0}$ & 0.0386 & 0.0394 & 0.0733 & 0.1110 & 0.0796 \\
$\mathbf{5 0}$ & 0.0371 & 0.0393 & 0.0680 & 0.0968 & 0.0748 \\
$\mathbf{6 0}$ & 0.0365 & 0.0373 & 0.0642 & 0.0761 & 0.0585 \\
$\mathbf{7 0}$ & 0.0356 & 0.0366 & 0.0975 & 0.0630 & 0.0559 \\
\hline
\end{tabular}

Table 7 Weighted normalized matrix for processed GGBS.

\begin{tabular}{|c|c|c|c|c|c|}
\hline Samples & $\begin{array}{l}\text { Specific } \\
\text { gravity }\end{array}$ & $\begin{array}{c}\text { Blaine } \\
\text { air permeability }\end{array}$ & Initial setting time & $\begin{array}{c}\text { Compressive strength } \\
7 \text { days }\end{array}$ & $\begin{array}{c}\text { Compressive strength } \\
28 \text { days }\end{array}$ \\
\hline $\mathbf{0}$ & 0.0338 & 0.0235 & 0.1031 & 0.0848 & 0.0649 \\
\hline 5 & 0.0338 & 0.0257 & 0.0864 & 0.0838 & 0.0646 \\
\hline 10 & 0.0338 & 0.0286 & 0.0751 & 0.0849 & 0.0671 \\
\hline 15 & 0.0335 & 0.0289 & 0.0672 & 0.0860 & 0.0684 \\
\hline 20 & 0.0332 & 0.0337 & 0.0625 & 0.0923 & 0.0683 \\
\hline 25 & 0.0332 & 0.0337 & 0.0598 & 0.0932 & 0.0661 \\
\hline 30 & 0.0330 & 0.0339 & 0.0771 & 0.0953 & 0.0690 \\
\hline 35 & 0.0326 & 0.0344 & 0.0705 & 0.0956 & 0.0707 \\
\hline 40 & 0.0326 & 0.0344 & 0.0632 & 0.1002 & 0.0692 \\
\hline 45 & 0.0323 & 0.0348 & 0.0711 & 0.1017 & 0.0695 \\
\hline 50 & 0.0318 & 0.0497 & 0.0738 & 0.0954 & 0.0710 \\
\hline
\end{tabular}

Table 8 A positive ideal solution and negative ideal solution for cinder.

\begin{tabular}{cccccc}
\hline & $\begin{array}{c}\text { Specific } \\
\text { gravity }\end{array}$ & $\begin{array}{c}\text { Blaine } \\
\text { air permeability }\end{array}$ & Initial setting time & $\begin{array}{c}\text { Compressive strength } \\
\mathbf{7} \text { days }\end{array}$ & $\begin{array}{c}\text { Compressive strength } \\
\text { 28 days }\end{array}$ \\
\hline $\mathbf{V}^{+}$ & 0.0415 & 0.0431 & 0.0642 & 0.1288 & 0.0923 \\
$\mathbf{V}^{-}$ & 0.0356 & 0.0366 & 0.1171 & 0.0630 & 0.0559 \\
\hline
\end{tabular}

Table 9 A positive ideal solution and negative ideal solution for processed GGBS.

\begin{tabular}{|c|c|c|c|c|c|}
\hline & $\begin{array}{l}\text { Specific } \\
\text { gravity }\end{array}$ & $\begin{array}{c}\text { Blaine } \\
\text { air permeability }\end{array}$ & Initial setting time & $\begin{array}{c}\text { Compressive strength } \\
7 \text { days } \\
\end{array}$ & $\begin{array}{c}\text { Compressive strength } \\
28 \text { days } \\
\end{array}$ \\
\hline $\mathbf{V}^{+}$ & 0.0338 & 0.0344 & 0.0598 & 0.0956 & 0.0707 \\
\hline $\mathbf{V}^{-}$ & 0.0326 & 0.0257 & 0.1031 & 0.0838 & 0.0646 \\
\hline
\end{tabular}

$$
\begin{aligned}
V^{-} & =\left\{\left(\sum_{i}^{\operatorname{Min}} \frac{V_{i j}}{j \in J}\right),\left(\sum_{i}^{\operatorname{Max}} \frac{V_{i j}}{j \in J}\right), i=1,2, \ldots, m\right\} \\
& =\left\{V_{1}^{-}, V_{2}^{-}, V_{3}^{-}, \ldots, V_{m}^{-}\right\}
\end{aligned}
$$

Step 5: Based on the positive ideal solution and negative ideal solution, calculate the distance of actual results from the positive ideal solution $\left(S_{i}^{+}\right)$and the distance from a negative ideal solution $\left(S_{i}^{-}\right)$known as separation, and calculated based on Eqs. (4) and (5) below.

$$
\begin{aligned}
& S_{i}^{+}=\sqrt{\sum_{j=1}^{n}\left(V_{i j}-V_{j}^{+}\right)^{2}} \\
& S_{i}^{-}=\sqrt{\sum_{j=1}^{n}\left(V_{i j}-V_{j}^{-}\right)^{2}}
\end{aligned}
$$

Step 6: After calculating the separations, the performance factor $P_{i}$ is calculated based on Eq. (8) (Rashid et al. 2017) for cinder and processed GGBS. The results are shown in Tables $\mathbf{1 0}$ and $\mathbf{1 1 .}$

$$
P_{i}=\frac{S_{i}^{-}}{S_{i}^{+}+S_{i}^{-}}
$$

\section{Cost and energy analysis}

The SCMs cinder and processed GGBS are readily available; having a lower cost gives economic and sustainable solutions compared to control cement concrete. As an example, Table 12 shows the comparative cost of M25 Grade (IS 10262 2009) of control cement concrete and prepares various concrete blends. The costs of cement, fine and coarse aggregate, and water were adopted based on the market survey. Since cinder and processed GGBS only require grinding before use with cement, its costs are low. Thus, the costs of cinder and processed GGBS are the same, as shown in Table 12. The replacement of cinder reduces the $20 \%$, and processed 
Table 10 Calculation of performance factor $\left(P_{i}\right)$ based on based on the positive and negative ideal solutions $\left(S_{i}^{+}\right.$and $S_{i}^{-}$) for cinder.

\begin{tabular}{ccccc}
\hline Samples & $S_{i}^{+}$ & $S_{i}^{-}$ & $P_{i}$ & Ranking \\
\hline $\mathbf{0}$ & 0.1015 & 0.1295 & 0.5607 & 0.5970 \\
$\mathbf{1 0}$ & 0.0837 & 0.1239 & 0.6192 & 5 \\
$\mathbf{3 0}$ & 0.0750 & 0.1219 & 0.6267 & 3 \\
$\mathbf{4 0}$ & 0.0698 & 0.1172 & 0.6416 & 0.6298 \\
$\mathbf{5 0}$ & 0.0594 & 0.1064 & 0.5265 & 2 \\
$\mathbf{6 0}$ & 0.0540 & 0.0918 & 0.3491 \\
\hline
\end{tabular}

Table 11 Calculation of performance factor $\left(P_{i}\right)$ based on the positive and negative ideal solutions $\left(S_{i}^{+}\right.$and $\left.S_{i}^{-}\right)$for processed GGBS.

\begin{tabular}{|c|c|c|c|c|}
\hline Samples & $S_{i}^{+}$ & $S_{i}^{-}$ & $P_{i}$ & Ranking \\
\hline $\mathbf{0}$ & 0.0567 & 0.0489 & 0.4634 & 11 \\
\hline 5 & 0.0540 & 0.0575 & 0.5160 & 10 \\
\hline 10 & 0.0535 & 0.0647 & 0.5474 & 8 \\
\hline 15 & 0.0530 & 0.0688 & 0.5648 & 6 \\
\hline 20 & 0.0542 & 0.0737 & 0.5763 & 3 \\
\hline 25 & 0.0547 & 0.0752 & 0.5792 & 2 \\
\hline 30 & 0.0521 & 0.0652 & 0.5557 & 7 \\
\hline 35 & 0.0519 & 0.0687 & 0.5699 & 5 \\
\hline 40 & 0.0509 & 0.0721 & 0.5860 & 1 \\
\hline 45 & 0.0497 & 0.0674 & 0.5758 & 4 \\
\hline 50 & 0.0712 & 0.0858 & 0.5464 & 9 \\
\hline
\end{tabular}

Table 12 Cost analysis for Grade M25 concrete per cubic meter.

\begin{tabular}{|c|c|c|c|c|c|c|}
\hline \multirow{2}{*}{ Sr. No. } & \multirow{2}{*}{ Material } & \multicolumn{2}{|c|}{ Quantity of material per $\mathrm{kg} / \mathrm{m}^{3}$} & \multirow{2}{*}{$\begin{array}{c}\text { Unit cost of } \\
\text { material per } R s / \mathrm{kg}\end{array}$} & \multicolumn{2}{|c|}{ Cost of material $\mathrm{Rs} / \mathrm{m}^{3}$} \\
\hline & & Control mix & C40 or M40 & & Control mix & C40 or M40 \\
\hline 1 & Cement & 335 & 201 & 6.00 & 2010.00 & 1206.00 \\
\hline 2 & $\begin{array}{c}\text { Cinder/ } \\
\text { processed GGBS }\end{array}$ & 0 & 134 & 1.50 & 0.00 & 201.00 \\
\hline 3 & Fine Agg. & 819 & 819 & 0.75 & 614.25 & 614.25 \\
\hline 4 & Coarse Agg. & 1163 & 1163 & 0.85 & 988.55 & 988.55 \\
\hline 5 & Water & 168 & 168 & 0.50 & 84.00 & 84.00 \\
\hline \multicolumn{4}{|c|}{ Total cost } & & 3696.80 & 3093.80 \\
\hline
\end{tabular}

GGBS reduces $16 \%$ overall material cost per meter cube.

The same benefits can be accepted in energy consumption when less cement is used in construction industries. The total specific energy consumption of different blends can be estimated using the equation below (Li et al. 2020).

$$
E_{t}=E_{c} \times\left(E_{c}-E_{S C M}\right) \times n \%
$$

where $E_{t}$ is the total special energy consumption, $E_{c}$ is the special energy consumption of cement clinkers, and $E_{S C M}$ special energy consumption by SCM. In India, cement production's special energy consumption is $88 \mathrm{kWh} / \mathrm{t}$ (Madlool et al. 2011). The specific energy consumption of cinder and processed GGBS depends upon the fineness of the particle. The particle's fineness directly depends on grinding; thus, the relationship between specific energy consumption and specific surface area is given in the equation below (Li et al. 2020). Here, the grinding energy of cement clinker, cinder, and processed GGBS is assumed similar in the present study.

$$
E_{g r i}=8.132 e^{0.4953 \frac{S S A}{100}}
$$

Substituting the value of the specific surface area of cement, cinder, and processed GGBS in the above equation. $\mathrm{E}_{\text {gri }}$ 's values for cement, cinder, and processed GGBS were $38.79,33.72$, and $80.08 \mathrm{kWh} / \mathrm{t}$. According to these values, the ratio of grinding energy to total energy for cement for cinder $38.79 / 88=44.07 \%$ is lower than the reported data in other literature (Madlool et al. 2011). Thus the saved energy extent $(\Psi)$ can be calculated by the following equation (Li et al. 2020).

$$
\Psi=\left\{1-\frac{E_{S C M}}{E_{c}}\right\} \times n \%
$$

Substituting the value of $\mathrm{E}_{\mathrm{c}}=88 \mathrm{kWh} / \mathrm{t}$ and $\mathrm{E}_{\mathrm{SCM}}=34$ $\mathrm{kWh} / \mathrm{t}$ for cinder and $\mathrm{E}_{\mathrm{SCM}}=80 \mathrm{kWh} / \mathrm{t}$ for processed GGBS, the value of the saved energy extent for cinder is $\Psi_{\mathrm{C}}=0.614 \times \mathrm{n} \%$ and for processed GGBS is $\Psi_{\mathrm{PG}}=0.09$ 
$\times \mathrm{n} \%$. According to this, a $40 \%$ replacement of cement by cinder can reduce $24.56 \%$, and a $40 \%$ replacement of cement by processed GGBS can reduce $3.6 \%$ of energy consumption. Hence, the cost and environmental aspects show that cinder and processed GGBS utilization is possible. If it achieves the required mechanical and durable properties of concrete, then cinder and processed GGBS benefit concrete and construction industries.

\section{Concluding remarks}

This examination was directed to research the impacts of utilizing SCMs (cinder and processed GGBS), a partial replacement of OPC on the different prepared blends' physical and mechanical properties. As indicated by the outcomes acquired in this work, the following conclusions could be made:

XRF results showed that all significant oxides $(\mathrm{CaO}$, $\mathrm{SiO}_{2}, \mathrm{Al}_{2} \mathrm{O}_{3}, \mathrm{Fe}_{2} \mathrm{O}_{3}, \mathrm{MgO}, \mathrm{SO}_{3}$ and alkalis $\left(\mathrm{Na}_{2} \mathrm{O}\right.$ and $\mathrm{K}_{2} \mathrm{O}$ ) available in material, which shows that in cinder, the content of $\mathrm{CaO}$ is $45 \%-50 \%$, and $\mathrm{SiO}_{2}$ is $5 \%$ to $10 \%$ wherein processed GGBS the content of $\mathrm{CaO}$ is $25 \%$ $30 \%$ and $\mathrm{SiO}_{2}$ is $40 \%$ to $45 \%$. The other available oxides like aluminum and iron oxides show that it is suitable to substitute as partial replacement of cement.

The following results were obtained by increasing the cement replacement level by cinder and processed GGBS.

1) There is no significant change observed in the available residue of different blends made with cement replacement with various processed GGBS and cinder dosages.

2) The specific gravity of the prepared blends decreases, and the value of archived specific gravities of various blends are near about the specific gravity of Portland pozzolana cement.

3) In the case of fineness, both the material shows different effects. Cinder decreases the fineness of prepared blends. Processed GGBS increases the fineness of prepared blends, which play a vital role in particle packing density, leading to a change in prepared blends or binders' compressive strength.

4) Increases the standard consistency; in addition to this, not much more effect on the soundness of prepared blends.

5) With increasing the cement replacement level by SCMs, both initial and final setting times show changes due to the decline of $\mathrm{C}_{3} \mathrm{~A}$ and $\mathrm{C}_{3} \mathrm{~S}$. More fineness in processed GGBS containing binder could result in a higher amount of water needed to reach the desired consistency in mortar mixtures.

6) The 28-day compressive strength would be approximately 85 percent to that of ordinary Portland cement for all binders. The experimental results show that the replacement of cinder and processed GGBS is possible up to $30 \%$ and $35 \%$, respectively. Presently, mortar studies may be different from concrete behavior.

7) According to the TOPSIS analysis, the optimum utilization of cinder and processed GGBS is $40 \%$ possible.

8) Cost analysis shows that $40 \%$ replacement of cement by cinder and processed GGBS can reduce the overall cost of the materials for M25 Grade concrete by $20 \%$ and $16 \%$, respectively.

9) Energy analysis shows that the $40 \%$ replacement of cement by cinder can reduce $24.56 \%$, and the processed GGBS can reduce 3.6\% energy consumption.

\section{Acknowledgments}

The authors would like to express gratitude toward Messrs. Dhaval, Gaurav, Sagar, Prajapati and their team (Civil Tech. Laboratory - Surat), Mr. Raj Chauhan (JEMS Multi Testing Laboratory - Surat), Mr. Ravi Bang (Chandrika Traders), Mr. Yogesh H. Varasada (Suyog Element India Pvt. Ltd.), and Mr. Jalpesh Sangani, Mr. Vishal Agrawal (Territory Technical Service Manager Ultratech Cement) for their extraordinary co-operation and backing. Additionally, the authors would like to thank the anonymous reviewers who helped to improve this paper with their constructive comments.

\section{References}

Abdelrazig, B. E. I., Sharp, J. H. and El-Jazairi, B., (1989). "The microstructure and mechanical properties of mortars made from magnesia-phosphate cement." Cement and Concrete Research, 19(2), 247-258.

Arandigoyen, M. and Alvarez, J. I., (2007). "Pore structure and mechanical properties of cement-lime mortars." Cement and Concrete Research, 37(5), 767-775.

Ganesan, K., Rajagopal, K. and Thangavel, K., (2007). "Evaluation of bagasse ash as supplementary cementitious material." Cement and Concrete Composites, 29(6), 515-524.

Horgnies, M., Chen, J. J. and Bouillon, C., (2013). "Overview about the use of Fourier transform infrared spectroscopy to study cementitious materials." WIT Transactions on Engineering Sciences, 77, 251-262.

Humbert, P. S. and Castro-Gomes, J., (2019). "CO2 activated steel slag-based materials: A review.” Journal of Cleaner Production, 208, 448-457.

IS 1489-2, (2015). "Portland-pozzolana cement: Part 2 Calcined clay based (Indian Standard IS 1489, Part 2)." New Delhi: Bureau of Indian Standards.

IS 1727, (2013). "Methods of test for pozzolanic materials (Indian Standard IS 1727)." New Delhi: Bureau of Indian Standards.

IS 4031-1, (2016). "Methods of physical tests for hydraulic cement: Part 1 Determination of fineness by dry sieving (Indian Standard 4031, Part 1)." New Delhi: Bureau of Indian Standards.

IS 4031-2, (2013). "Methods of physical tests for hydraulic cement: Part 2 Determination offineness by Blaine air permeability method (Indian Standard IS 4031, Part 2)." New Delhi: Bureau of Indian Standards.

IS 4031-3, (2019). "Methods of physical tests for hydraulic cement: Part 3 Determination of soundness (Indian 
Standard IS 4031, Part 3).” New Delhi: Bureau of Indian Standards.

IS 4031-4, (2019). "Methods of physical tests for hydraulic cement: Part 4 Determination of consistency of standard cement paste (Indian Standard IS 4031, Part 4)." New Delhi: Bureau of Indian Standards.

IS 4031-5, (2019). "Methods of physical tests for hydraulic cement: Part 5 Determination of initial and final setting times (Indian Standard IS 4031, Part 5)." New Delhi: Bureau of Indian Standards.

IS 4031-11, (2013). "Methods of physical tests for hydraulic cement: Part 11 Determination of density (Indian Standard 4031, Part 11)." New Delhi: Bureau of Indian Standards.

IS 650, (2018). "Standard sand for testing cement (Indian Standard IS 650)." New Delhi: Bureau of Indian Standards.

IS 10262, (2019), "Concrete mix proportioning - Guidelines (Indian Standard IS 10262).” New Delhi: Bureau of Indian Standards.

Kosmatka, S. H. and Wilson, M. L., (2011). "Design and control of concrete mixtures - The guide to applications, methods and materials." $15^{\text {th }}$ ed. Illinois: The Portland Cement Association.

Kumar, M. P., Mini, K. M. and Rangarajan, M., (2018). "Ultrafine GGBS and calcium nitrate as concrete admixtures for improved mechanical properties and corrosion resistance." Construction and Building Materials, 182, 249-257.

Kupwade-Patil, K., Palkovic, S. D., Bumajdad, A., Soriano, C. and Büyüköztürk, O., (2018). "Use of silica fume and natural volcanic ash as a replacement to Portland cement: Micro and pore structural investigation using NMR, XRD, FTIR and X-ray microtomography." Construction and Building Materials, 158, 574-590.

Li, L., Liu, W., You, Q., Chen, M. and Zeng, Q., (2020). "Waste ceramic powder as a pozzolanic supplementary filler of cement for developing sustainable building materials." Journal of Cleaner Production, 259, Article ID 120853.

Madlool, N. A., Saidur, R., Hossain, M. S. and Rahim, N. A., (2011). "A critical review on energy use and savings in the cement industries." Renewable and Sustainable Energy Reviews, 15(4), 2042-2060.

Mamlouk, M. S. and Zaniewski, J. P., (2011). "Materials for civil and construction engineers." London: Pearson PLC.

Mehta, P. K. and Monteiro, P. J. M., (2017). "Concrete microstructure, properties and materials." New York: McGraw-Hill Education.

Mo, L., Zhang, F. and Deng, M., (2016). "Mechanical performance and microstructure of calcium carbonate binder produced by cabonating steel slag paste under $\mathrm{CO}_{2}$ curing." Cement and Concrete Research, (88), 217-226.

Mohan, A. and Mini, K. M., (2018). "Strength and durability studies of SCC incorporating silica fume and ultra fine GGBS." Construction and Building Materials,
171, 919-928.

Narender Reddy, A. and Meena, T., (2018). “A study on compressive behavior of ternary blended concrete incorporating Alccofine." Materials Today, 5(5-2), 11356-11363.

Nicolae, M., Vîlciu, I. and Zăman, F., (2007). "X-ray diffraction analysis of steel slag and blast furnace slag viewing their use for road construction." University Politehnica of Bucharest Scientific Bulletin, Series B: Chemistry and Materials Science, 69(2), 99-108.

Nilesen, A. U. and Monteiro, P. L. M., (1993). "Concrete: A three phase material." Cement and Concrete Research, 23, 147-151.

Parveen, J., Singhal, D., Junaid, M. T., Jindal, B. B. and Mehta, A., (2018). "Mechanical and microstructural properties of fly ash based geopolymer concrete incorporating Alccofine at ambient curing." Construction and Building Materials, 180(2018), 298-307.

Ramesh, B. A. and Kondraivendhan, B., (2020). "Effect of accelerated carbonation on the performance of concrete containing natural zeolite." Journal of Materials in Civil Engineering, 32(4), 1-10.

Rao, R. V., (2013). "Decision making in the manufacturing environment." London: Springer-Verlag.

Rashid, K., Hameed, R., Ahmad, H. A., Razzaq, A., Ahmad, M. and Mahmood, A., (2017). "Experimental and analytical selection of sustainable recycled concrete with ceramic waste aggregate." Construction and Building Materials, (157), 829-840.

Rashid, K., Hameed, R., Ahmad, H. A., Razzaq, A., Ahmad, M. and Mahmood, A., (2018). "Analytical framework for value added utilization of glass in concrete: Mechanical and environmental performance." Waste Management, (79), 312-323.

Rezaee, F., Danesh, S., Tavakkolizadeh, M. and Mohammadi-Khatami, M., (2019). "Investigating chemical, physical and mechanical properties of eco-cement produced using dry sewage sludge and traditional raw materials." Journal of Cleaner Production, 214, 749-757.

Saloni, A., Singh, A., Sandhu, V., Jatin, A. and Parveen, J., (2020). "Effects of Alccofine and curing conditions on properties of low calcium fly ash-based geopolymer concrete." Materials Today: Proceedings, 32(4), 620-625.

Siddique, R. and Khan, M. I., (2011). "Supplementary cementing materials." Berlin and Heidelberg: Springer-Verlag.

Taylor, H. F. W., (1989). "Modification of the Bogue calculation." Advances in Cement Research, 2(6), 73-77.

Teng, S., Lim, T. Y. D. and Divsholi, B. S., (2013). "Durability and mechanical properties of high strength concrete incorporating ultra fine ground granulated blast-furnace slag." Construction and Building Materials, 40, 875-881.

Tsakiridis, P., Papadimitriou, G. D., Tsivilis, S. and Koroneos, C., (2008a). "Utilization of steel slag for 
Portland cement clinker production." Journal of Hazardous Materials, 152(2), 805-811.

Tsakiridis, P., Papadimitriou, G. D., Tsivilis, S. and Koroneos, C., (2008b). "Utilization of steel slag for Portland cement clinker production." Journal of Hazardous Materials, 152(2), 805-811.

Yi, H., Xu, G., Cheng, H., Wang, J., Wan, Y. and Chen, H., (2012). "An overview of utilization of steel slag." Procedia Environmental Sciences, 16, 791-801.
Yildirim, I. Z. and Prezzi, M., (2011). "Chemical, mineralogical, and morphological properties of steel slag." Advances in Civil Engineering, 2011, Article ID 463638.

Yücel, H. E. and Özcan, S., (2019). "Strength characteristics and microstructural properties of cement mortars incorporating synthetic wollastonite produced with a new technique." Construction and Building Materials, $223,165-176$. 